Luis Hachim

Universidad de Santiago de Chile

luis.hachim@usach.cl

Pablo Hurtado

Universidad de Santiago de Chile

pablo.hurtado@usach.cl

\title{
El discurso factual y ficcional en la narrativa colonial hispanoamericana: Naufragios [1542] de Alvar Núñez Cabeza de Vaca e Infortunios de Alonso Ramírez [1690] de Carlos de Sigüenza y Góngora.
}

\section{Tensions between the Factual and Fictional Discourses in Colonial Narratives: Masking Strategies in Naufragios [1542] by Alvar Núñez Cabeza de Vaca and Infortunios de Alonso Ramírez [1690] by Carlos Sigüenza y Góngora.}

\footnotetext{
Resumen

Este trabajo se constituye a partir de la narrativa como experiencia, acción y proceso permanente en el periodo Colonial hispanoamericano. Con la ratificación de esta narrativa, trataremos dos textos que se producen en la etapa colonial. Este periodo marcado por el proceso de constitución del pensamiento criollo, es coherente con toda narración inscrita en Libros de viajes, Relaciones, Crónicas, conformando una síntesis entre el discurso factual y el discurso ficcional, en textos que representan no solo las transformaciones del sujeto español indiano, sino también la emergente subjetividad criolla que caracteriza la nueva cultura y su relación conflictiva con el mundo indígena. Por ello, este trabajo propone una primera etapa, incorporando dos obras paradigmáticas, desafectadas de la preocupación de los estudios literarios e historiográficos: 1) Naufragios [1542] de Alvar Núñez Cabeza de Vaca. 2) Infortunios de Alonso Ramírez [1690] de Carlos de Sigüenza y Góngora. Ambas narrativas a través de estrategias factuales enmascararon la composición ficcional, procedimientos que
} 
CATEDRAL TOMADA: Revista de crítica literaria latinoamericana / Journal of Latin American Literary Criticism El discurso factual y ficcional en la narrativa colonial hispanoamericana: Naufragios [1542] de Alvar Núñez Cabeza de Vaca e Infortunios de Alonso Ramírez [1690] de Carlos de Sigüenza y Góngora.

después se incorporarían con toda propiedad, a las prácticas y escrituras características en las Literaturas de América.

Palabras claves Estudios coloniales, Estudios narrativos, Alvar Núñez Cabeza de Vaca, Carlos de Sigüenza y Góngora.

\begin{abstract}
This paper is based on the assumption that narratives are ongoing experiences, actions and processes that take place during the Colonial period. On these grounds, two narrative texts from the beginnings of the colonial formation period will be discussed. Narratives during this period when a vernacular, creole consciousness was being shaped are coherent with the narrations found in travel journals, relaciones and chronicles. A synthesis of factual and fictional discourses arises in these texts that represent not only the identity transformations of the Indian Spanish individual but also the emerging local, creole subjectivity that defines the new culture and its relations with indigenous world. We suggest a first stage in this cultural synthesis that includes two texts that have not been addressed literary and historiographic studies: Naufragios [1542] by Alvar Núñez Cabeza de Vaca and Infortunios de Alonso Ramírez [1690] by Carlos de Sigüenza. These two founding narratives used a factual discourse that masked the fictional strategies that were later included in the textual practices that characterize the literatures of the Americas.
\end{abstract}

Keywords Colonial studies, Narrative studies, Alvar Núñez Cabeza de Vaca, Carlos de Sigüenza y Góngora.

La novela como tal es una forma de nostalgia.

David Shields

Para efectos de este estudio, nos parece indispensable centrar el enfoque en la narración, entendida como una acción básica y transversal en la mayoría de los textos escritos entre el siglo XV y el XVIII en el contexto hispanoamericano. Esta narración, implica un producto, la narrativa entendida como resultado y proceso; "conversión de la lengua en discurso" (Reis, sub voquem, 2002) e incluso registro o escritura simple del "relato [...] de eventos y conflictos que configuran el desarrollo de una acción" (Ibid) y de hechos en el tiempo, transformada posteriormente en una constante de la producción letrada colonial. En este sentido, la opción por la narrativa, implica recusar la influencia de la novela en el periodo. Ciertamente que El periquillo Sarniento (1816) de José Joaquín Fernández de Lizardi, constituye "el comienzo de la tradición novelística en México" (Ruiz, 9) e Hispanoamérica. Junto a José Anadón (2015: 230) y las hipótesis sobre la novela colonial, sobresale igualmente C. Goic, quien estudió el problema de la novela hispanoamericana, identificando 
obras de carácter histórico, que incurren en el tipo intencional de préstamos poéticos esporádicos cuando, con propósitos de amenidad esencialmente, alteran la situación narrativa real o de escritura, creando una situación narrativa de ficción variadamente elaborada, o bien para mantener una cercanía con el relato oral y extremo, imitan su situación fingiendo una narración autobiográfica. El Lazarillo de ciegos caminantes (1773), un libro de viajes, y los Infortunios de Alonso Ramírez (1690), una biografía, representan este grupo. (Goic, 374-375)

Para la Dra. Invernizzi, la complejidad de estos textos, se debería a:

La incongruencia entre materia y tipo discursivo, unida al hecho de que estos discursos son producto de un acto de enunciación y no respuesta a un mandato oficial, y de que la finalidad de ellos no es sólo la informativa, advierten sobre los desajustes de Naufragios e Infortunios con los modelos historiográficos del momento; desajustes que se ahondarán por la presencia, en el interior de los discursos, de elementos reconocibles como pertenecientes a otras formaciones discursivas, los que confieren a estos textos un carácter mixto del cual ha derivado el problema de su indeterminación genérica y de su clasificación indistinta ya sea como obras historiográficas o de ficción novelesca. (Invernizzi, 8)

Tanto Goic, que nos refiere a "obras de carácter histórico y narrativa de ficción" como Invernizzi, reiteran la oposición entre "obras historiográficas o de ficción novelesca" a propósito de Naufragios [1542] de Alvar Núñez Cabeza de Vaca e Infortunios de Alonso Ramírez [1690] de Carlos de Sigüenza y Góngora. Estas oposiciones se reiteran en la crítica, insistiendo en la oscilación entre lo histórico y lo ficticio.

Para efectos de un corpus de trabajo, en el periodo de la Colonia, creemos que este mismo problema afectaría La peregrinación de Bartolomé Lorenzo [1586], La Araucana [1574-1589], Comentarios reales de los Incas (1609), Nueva Corónica y buen gobierno [1615], Historia de la monja alférez, Catalina de Erauso, escrita por ella misma [1653], Cautiverio feliz [1673], Los infortunios de Alonso Ramírez [1690], El lazarillo de ciegos caminantes [1776] por citar solo algunas obras pertinentes. Incorporar estos textos al conocimiento de la cultura colonial y letrada hispanoamericana, significa despejar equívocos conceptuales como, novelas barrocas o proto novelas. Por ello, más que discutir la presencia de novela en la América hispánica, nos parece más provechoso estudiar la narrativa que subyace en la mayoría de los textos, incluso más allá de la forma de la expresión.

Digamos, frente a lo anterior, que en el contexto colonial hispanoamericano se impuso un criterio "realista" y Autorial, narrativamente determinado por la necesidad de informar y referir los hechos de la conquista, junto con mantenerse a resguardo de las prohibiciones de escribir mentirosas historias, que implicaban 
obstáculos para la evangelización y dificultaban la comprensión de santas y católicas doctrinas para la instrucción de los indios. Observemos estas dos Leyes, entre otras, contenidas en el Libro I, Título XXIV de la Recopilación de Leyes de Indias, vigentes a partir de $1550^{1}$ :

Ley iiij [4]. Que no se consientan en las Indias libros profanos y fabulosos. Porque de llevarse a las Indias libros de Romance, que traten de materias profanas $\mathrm{y}$ fabulosas e historias fingidas, se siguen muchos inconvenientes. Mandamos a los Virreyes, Audiencias y Gobernadores que no los consientan imprimir, vender, tener ni llevar a sus distritos y procuren que ningún español ni indio los lea. (Recopilación ..., fol. 123)

\section{Ley vij [7]. Que los Prelados, Audiencias y Oficiales Reales reconozcan} y recojan los libros prohibidos, conforme a los Expurgatorios de la Santa Inquisición.

Nuestros Virreyes, Presidentes y Oidores pongan por su parte toda la diligencia necesaria, y den orden a los oficiales Reales para que reconozcan en las visitas de Navíos si llevan algunos libros prohibidos, conforme a los Expurgatorios de la Santa Inquisición y hagan entregar todos los que hallaren a los Arzobispos, Obispos o a las personas a quien corresponda por acuerdo del Santo Oficio. Y rogamos y encargamos a los Prelados Eclesiásticos que por todas las vías posibles averigüen y procuren saber si en sus diócesis hay algunos libros de esta calidad y los recojan y hagan de ello lo ordenado por el Consejo de la Inquisición y no consientan, ni den lugar a que permanezcan ni queden en aquellas Provincias. (Recopilación..., fol. 124)

Las prohibiciones de libros fabulosos que podrían tratar historias fingidas determinaron, en parte, que la narrativa factual de la conquista y establecimiento colonial en las nuevas tierras, enmascaró la ficción para eludir penas aflictivas, juicios, e incluso excomunión. Por eso, sobre todo en el periodo colonial hispanoamericano (siglos XV al XVIII) podemos desligarnos de la hipótesis de una novelística en América, considerando además que su inexistencia no constituye una denegación de la cultura criolla. Aclaro que estas observaciones no implican rechazo al pensamiento, que ve el desarrollo de la novela hispanoamericana, como continuidad de la novela europea, aunque esa cuadratura produzca formulaciones como "no hubo ni una sola novela en la América colonial” como aseguró Gonzalo Celorio (Calderón). A su vez, Juan José Saer afirmó que: "la novela es únicamente un periodo de la narración, [...] la narración se transforma en novela en los siglos XVII y XIX y se convierte en la forma literaria por excelencia de la época burguesa" (Saer, 144). Entonces, proponemos en función del problema, que estas escrituras históricas y/o literarias, no sería más que una síntesis de lo factual y

\footnotetext{
${ }^{1}$ En lo fundamental hemos modernizado la escritura.
} 
ficcional, configuradas en la narración colonial ${ }^{2}$ hispanoamericana, con todo lo que implica esta denominación fundacional. Esta síntesis reafirma la propuesta y demarcación del problema. No correspondía optar en ese momento por lo fáctico o lo ficcional, sino que en esos textos, la síntesis implicó la conjunción de ambos discursos en una sola narrativa.

Consecuentemente, abordaremos al respecto dos textos ejemplares: Naufragios (1542) de Alvar Núñez Cabeza de Vaca e Infortunios de Alonso Ramírez (1690) de Carlos de Sigüenza y Góngora ${ }^{3}$. Este corpus básico ${ }^{4}$ implica un programa o heurística literaria que reafirma el acto de narrar, es decir, considera la narrativa como práctica transversal y continua en la cultura Colonial ${ }^{5}$. Narrativa que necesita más estudio por parte de la "teoría" y la "crítica" de la Literatura y que tampoco ha sido parte de las preceptivas, que refieren algunas obras del periodo, a pesar del amplio catálogo de textos escritos entre los siglos XV y XVIII. En el repertorio narrativo colonial hispanoamericano, llaman la atención estos textos, cuyo estatuto es complejo o más bien anómalo, pues en la lectura de la crítica no satisfacen ni las demandas literarias ni tampoco las historiográficas. Paradójicamente, estos libros constituyeron el archivo de una narrativa que acercó a los letrados y lectores de esa época al mundo americano.

Como parte de un proyecto en curso, estos dos textos, Naufragios (1542) e Infortunios de Alonso Ramírez (1690), constitutivos de la narrativa Colonial hispanoamericana y escritos en el siglo XVI y XVII respectivamente, implican una primera aproximación, en perspectiva de tratar fundamentalmente esa especial relación entre el discurso que informó hechos y el discurso que desarrolló estrategias de composición y trama.

La variedad de registros, que tomaron como referente los hechos de conquista y el proceso colonial hispanoamericano, son casi inabarcables. El texto histórico, crónicas e incluso "novelas" 6 (escritas en la península) que tematizaron lo ocurrido entre los siglos XV y principios del XIX, constituyeron formas que, como otras, implican una narratividad ${ }^{7}$ acorde al periodo señalado. Tanto en la zona de la América septentrional (norte) como meridional (centro y sur), todo estudio de un corpus viable, implica reconocer que la narrativa fue la experiencia

${ }^{2}$ Covarrubias Horozco, Sebastián de (2006) [1611]: Tesoro de la lengua Castellana. Madrid: Iberoamericana Colonia. Es puebla o término de tierra que se ha poblado de gente extranjera, sacada de la ciudad que es señora de aquel territorio o llevada de otra parte. Suv boquem.

${ }^{3}$ El interés por el Barroco de Indias, Infortunios y la idea de novelas enmascaradas, se debe a las propuestas de Claudia Ormeño E. (2008): Narrativa del Barroco de Indias: Tres obras ocultas bajo la máscara realista. (Tesis de pre grado dirigida por el Dr. Nelson Osorio Tejeda). Universidad de Santiago de Chile.

${ }^{4} \mathrm{Al}$ que agregaríamos en articulo aparte El Lazarillo de ciegos caminantes (1773) de Alonso Carrió de la Vandera y representativo del siglo XVIII.

5 La Colonia hispanoamericana (también la Colonialidad) constituye un sistema políticoadministrativo y militar definido por tres ejes: raza, eurocentrismo y el eje capitalista, en acuerdo con las propuestas de Aníbal Quijano (2000).

${ }^{6}$ Covarrubias Horozco, Sebastián: opus cit. "un cuento bien compuesto o patraña para entretener los oyentes, como las novelas de Bocaccio", suv boquem.

${ }^{7}$ Tomamos el concepto de Carlos Reis (2002). 
común en toda esta diversidad, como acción enunciativa transversal en bitácoras, diarios, informes, relaciones, crónicas, historias, cartas, noticias, comentarios, biografías y otras escrituras del periodo Colonial y primer segmento de la Colonialidad. Ello permite que, más allá del género, estos textos sean estudiados como escritura, puesto que según John Searle no existiría "propiedad textual, sintáctica o semántica [ni, narratológica] que permita identificar un texto como obra de ficción" (Genette, 55) ni diferenciarlo de una obra factual [agregado de Hachim y Hurtado]. Más aún, en el flujo del enunciado, tampoco es posible diferenciar el referente real del imaginado. Entonces, en los estudios del periodo hispanoamericano, la oposición realidad-ficción es inocua, en tanto no da sustento al problema ${ }^{8}$. Por el contrario, importa más distinguir en esta narrativa la síntesis que unificó la relación discurso ${ }^{9}$ factual-ficcional. Al respecto, en una revisión breve, ya planteada en una etapa inicial por Beatriz Pastor, certificaba que "este discurso narrativo se define, en primera instancia, por su objeto declarado: la narración directa de los hechos concretos del proceso de descubrimiento, exploración y conquista de las tierras del Nuevo Mundo" (Pastor, 8). Rolena Adorno (1988) a su vez, propuso que en los estudios coloniales, se debería utilizar el concepto de discurso en reemplazo de otras nociones, ya sea históricas e incluso también literarias. González Echevarría en Myth and archive. A theory of Latin American narrative (1990) escribió que las primeras narrativas en América, imitaron el discurso de la ley. Por último, Stephanie Merrim: "Los Naufragios de Núñez es una de las obras más ricas de la primera narrativa colonial" (Merrim, 114). Estas perspectivas distintas, paradojalmente sirven a nuestra propuesta, en tanto reconocen que la experiencia común fue narrativa.

Entendemos que postular la narración como eje, implica igualmente desentenderse de la oposición realidad/ficción y la cadena de temas (no problemas) que implica. Se trata de llamar la atención sobre aquellas obras en las cuales se establece una síntesis estructural y creativa entre el discurso factual que refiere los hechos de la conquista y colonia — con sus correspondientes evidencias ${ }^{10}$ - y el discurso ficcional que incorporó estrategias de fabulación (formas de componer) en la misma narrativa ${ }^{11}$. En el siglo XVII Covarrubias en su Tesoro de la Lengua, registra la palabra ficion oficción entendida como "Cosa fingida o compuesta como las fábulas o los argumentos de las comedias,...".

${ }^{8}$ Más que la realidad, interesa la evidencia como problema narrativo, haciendo de bisagra entre el enunciado y la enunciación, por ejemplo el viaje de Alvar Núnez Cabeza de Vaca en la expedición de Pánfilo de Narváez en 1527, constituye la evidencia inicial que abre la narración de las peripecias del Autor $=$ Narrador $=$ Personaje.

9 A partir de esta concepción de Discurso, entenderemos que es posible asimilar discurso (ver discurso narrativo en Reis) al término narrativa.

${ }^{10}$ Evidencias que nos conectan permanentemente con la enunciación y que están determinadas por criterios clasificatorios, comparativos y cuantitativos. Abbagnano, Nicola (2010): Diccionario de Filosofía. México. FCE. 436-438.

${ }^{11}$ Esta propuesta declara su cercanía con Ficcion in the Archives (1987) de Natalie Zemon Davis, pero entendiendo la ficcionalización como parte constitutiva de la construcción narrativa. 
Acorde con las acepciones precedentes, nos interesa más al segundo sentido: la Ficción como forma de composición. La ficción como cosa fingida (en términos de imaginación), es decir, el primer sentido, hasta ahora ha dominado el análisis, institucionalizando la oposición ficción vs realidad, simplificando el estudio, pero siendo finalmente un obstáculo de conocimiento. Por otro lado, la narrativa factual no ha tenido la atención e investigación, que ha sobrado en el caso de la narrativa ficcional (Genette, 53). Por esto enfatizamos el segundo sentido, la ficción como forma de composición. El mismo Covarrubias profundiza en ese tipo de ficción

compuesta como las fábulas", [...] alguna veces damos nombres de fábulas a las cosas que fueron ciertas y verdaderas, pero en su discurso tienen tanta variedad que parecen cosas no acontecidas sino compuestas e inventadas de algún gallardo y lozano ingenio. Los que habéis leído las corónicas de las Indias, cosa que pasó ayer, tan cierta y tan sabida, mirad cuantas cosas hay en su descubrimiento y en su conquista, que exceden a cuanto han imaginado las plumas de los vanos mentirosos que han escrito libros. $^{12}$

La narrativa, registro y composición de los hechos en el contexto que incorpora esta investigación, se abordará desde: a) la Situación narrativa (Stanzel, 1984) y el Pacto Autor-Narrador-Personaje (Lejeune, 1994) y b) la Poética narrativa (Estructura. representación y lenguaje) (Doležel, 1997). Estas dos instancias, caracterizarán los textos nombrados y producidos entre los siglos XVI, XVII en la América hispánica, para estudiar la narrativa que involucra hechos y la forma de componer estos hechos. En un artículo previo sobre el problema (Hachim, 2010) se desarrolló una primera aproximación a las narrativas del periodo, ante la necesidad de "profundizar narratológicamente en los textos que configuran el corpus, incorporando también los que han sido excluidos y pertenecen [sin embargo] al archivo Colonial" (23). En segunda instancia; se trata de constatar otras transformaciones narrativas en su transición al siglo XIX (cambios en la narrativa Colonial, en transición a las narrativas de la Colonialidad).

\section{II}

En general, Naufragios e Infortunios son textos representativos de esta narrativa en tanto incorporaron el relato factual y ficcional, puesto que no solo se cuentan hechos e información de la expedición de Pánfilo de Narváez, sino su estructura evidencia una composición que hace coincidir el discurso (como se cuenta) con la historia (qué se cuenta).

En concreto, 1) Naufragios se caracteriza por una Situación narrativa Autorial (SA): Alvar Núñez Cabeza de Vaca construye un precedente, ya que desde

${ }^{12}$ Covarrubias Horozco, Sebastián de, (2006) [1611]: Tesoro de la Lengua Castellana o Española. Madrid: Iberoamericana, sub voquem. 
la Autorización, Prohemio y Capítulos (primero al treinta y ocho) se asume como Autor y al mismo tiempo Narrador y Personaje:

no me quedó lugar para hacer más servicio deste, que es traer a Vuestra Magestad relación de lo que en diez años que por muchas y muy estrañas tierras que anduve perdido y en cueros, pudiesse saber y ver, ansí en el sitio de las tierras y provincias y distancias dellas como en los mantenimientos y animales que en ellas se crían y las diversas costumbres de muchas y muy bárbaras naciones con quien conversé y viví, y todas las otras particularidades que pude alcanzar y conocer, que dello en alguna manera Vuestra Magestad será servido, porque aunque la esperanza que de salir de entre ellos tuve siempre fue muy poca, el cuidado y diligencia siempre fue muy grande de tener particular memoria de todo. (Núñez Cabeza de Vaca, 80-81)

El Autor se vincula a un Narrador, que desde el 17 de junio de 1527 inicia su relato a partir de una evidencia histórica inicial:

A diez y siete días del mes de Junio de mil quinientos y veinte y siete partió del puerto de Sant Lúcar de Barremeda el governador Pámphilo de Narváez, con poder y mandado de Vuestra Majestad para conquistar y governar las provincias que están desde el río de las Palmas hasta el cabo de la Florida, las cuales son en tierra firme. Y la armada que llevava eran cinco navíos, en los cuales, poco más o menos, irían seiscientos hombres. Los officiales que llevava (porque dellos se ha de hazer mención) eran éstos que aquí se nombran: Cabeça de Vaca, por thesorero y por alguazil mayor. (Núñez Cabeza de Vaca, 83-84)

La constatación de la situación narrativa, por otra parte se expresa también en la perspectiva personal del Narrador:

vimos un animal [zarigüeya] que trae los hijos en una bolsa que en la barriga tiene, y todo el tiempo que son pequeños los traen allí hasta que saben buscar de comer, y si acaso están fuera buscando de comer y acude gente, la madre no huye hasta que los ha recogido en su bolsa. (102)

La relación $\mathrm{A}$ (utor) $=\mathrm{N}$ (arrador $)=\mathrm{P}($ ersonaje) constituye un enunciado que caracteriza la situación autorial desde el punto de vista narrativo, como se reafirma en el final del capítulo treinta y siete: "lo firme de mi nombre. Cabeza de Vaca..." (210). Este pacto en Naufragios, permite una narración que equilibra el estatuto del mundo narrado (lector enunciado) con el referente (mundo donde ocurre el proceso de enunciación). El sentido de la narración, se logra, proyectando el enunciado en la enunciación. El autor, también el Lector, vincula la realidad con el mundo 
narrado, a través del Narrador y la relación de hechos, que igualmente involucran al Personaje $(\mathrm{A}=\mathrm{N}=\mathrm{P})$.

Frente a los relatos mitificadores, que abusaron del modelo mítico, para explicar el mundo americano, y luego la avalancha épica de los sujetos heroicos en los relatos del conquistador, esta obra, contradice esas versiones reiteradas en Cartas, Relaciones y Crónicas, donde el efecto narrativo revela una realidad engañosa que esos textos maestros habían relatado como propios de lo americano, permitiendo así la crítica y reflexión sobre la realidad narrada (lector). Pastor habla de narraciones del fracaso (B. Pastor: 1983). Cabeza de Vaca, el narrador, uno de los cuatro sobrevivientes de los 600 hombres que salieron desde España y que luego se internaron por el norte de México; evidencia geográfica, (ahora sur de Estados Unidos) asume el peregrinaje y las diferentes peripecias, esclavo de los muscogis, buhonero, curandero itinerante de Tampa a los Apalaches, viajero por Mobile, Pensacola:

Yo le toqué y sentí la punta de la flecha vi que la tenía atravesada por la ternilla, y con un cuchillo que tenía le abrí el pecho hasta aquel lugar y vi que tenía la punta atravessada y estaba muy mala de sacar; torné a cortar más y metí la punta del cuchillo y con gran trabajo en fin la saqué. Era muy larga y con un hueso de venado, usando de mi officio de medicina le di dos puntos. (Núñez Cabeza de Vaca, 178)

El contacto de Cabeza de Vaca con seminolas, sioux, dakotas, hans, chorrucas, transforma al tesorero y alguacil mayor, que inició su viaje en 1527 y que en una primera instancia escribió: "porque toda esta gente de indios son grandes amigos de novelas y muy mentirosos" (176) sin privarse de sus juicios:

En el tiempo que así estaba entre éstos ví una diablura, y es que ví un hombre casado con otro, y esto son unos hombres amarionados, impotentes, y andan tapados como mujeres y hacen officio de mujeres tiran arco y llevan muy grande carga; y entre estos vimmos muchos dellos, así amarionados como digo, y son más membrudos que los otros hombres y más altos, sufren muy grandes cargas. (168)

Posteriormente, Cabeza de Vaca, irremediablemente indiano al regresar a España en 1540, ya es Otro. Como indiano o ladino inverso, traduce desde la lengua indígena:

los christianos mentían, porque nosotros [según los indios] veníamos de donde salía el sol y ellos donde se pone, y que nosotros sanávamos a los enfermos y ellos matavan a los que estaban sanos, y que nosotros veníamos desnudos y descalzos y ellos vestidos y en caballos y con lanzas, y que nosotros no teníamos codicia de ninguna cosa, antes todo cuando nos daban tornávamos luego a dar y con nada nos quedábamos, y los otros no 
CATEDRAL TOMADA: Revista de crítica literaria latinoamericana / Journal of Latin American Literary Criticism El discurso factual y ficcional en la narrativa colonial hispanoamericana: Naufragios [1542] de Alvar Núñez Cabeza de Vaca e Infortunios de Alonso Ramírez [1690] de Carlos de Sigüenza y Góngora.

tenían otro fin sino robar todo cuanto hallavan y nunca daban nada a nadie... (198-199)

La narración de este autor/narrador/personaje se define como "relación" y "memoria" en el Prohemio, mostrando el lugar del discurso factual, en el relato de una de las más ejemplares expediciones a La Florida: entonces cómo entender el enmascaramiento de la ficción: asumiendo que tanto los hechos que no implican evidencias y los que implican evidencias, solo se constituyen el enunciado narrativo. El relato de las brutales peripecias y el hambre, son consustanciales a la condición de los españoles: "comenzóse a morir la gente, y cinco christianos que estaban en rancho en la costa llegaron a tal estremo que se comieron los unos a los otros hasta que quedó uno sólo, que por ser solo no hubo quien lo comiesse" (127). Esta cruda descripción contradice el segmento que el narrador refirió anteriormente: "Los animales que en ellas vimos son venados de tres maneras, conejos liebres, osos y leones [...] por allí la tierra [...] tiene muy buenos pastos para ganados; ay aves de muchas maneras; ánsares en gran cantidad, patos, ánades, patos reales, dorales y garzotas y garzas, perdices" (102). Esta abundancia ${ }^{13}$ paradisiaca, pareciera oponerse a la imitación del Cristo sufriente. Dejo a consideración este fragmento:

Los indios, de ver el desastre que nos avía venido y el desastre en que estábamos con tanta des ventura y miseria, se sentaron entre nosotros y con el gran dolor y lástima que ovieron de vernos en tanta fortuna, començaron todos a llorar rezio y tan de verdad que lexos de allí se podía oír, y esto les duró más de media hora. (124)

Por otro lado, la transformación de Cabeza de Vaca, parte de la evidencia autobiográfica, en el paso a su conversión en Indiano, también es corolario de un valor narrativo superior:

Y otro día de mañana alcancé cuatro christianos de caballo que rescibieron gran alteración de verme tan estrañamante vestido y en compañía de indios. Estuviéronme mirando mucho espacio de tiempo, tan atónitos que ni me hablavan ni acertaban a preguntarme nada. (196)

Para otros casos, podemos reconstituir el registro de evidencias, que mostrarían esta síntesis entre lo factual y ficcional resuelta como narrativa colonial hispanoamericana.

\section{III}

${ }^{13}$ En la edición de Alianza, que manejamos en este trabajo, se registra que esta descripción corresponde al Paraíso literaturizado (nota 43). 
A su vez, Infortunios de Alonso Ramírez de Carlos de Sigüenza y Góngora de 1690, muestra que la situación autorial también es determinante, aunque el Autor no muestra identidad con el Narrador, que en este caso es Alonso Ramírez y también Personaje: $\mathrm{A} \neq \mathrm{N}=\mathrm{P}$. La narrativa en este aspecto implica, un Autor (editor) Siguenza y Góngora como entidad organizadora e incorporando su mirada en el relato de Alonso Ramírez, a través de textos nuncupatorios, el orden y encabezamiento de cada uno de los capítulos (uno al siete). En este último, el Autor adquiere ser literario para Lagmanovich (1988) y esto se apreciaría en el siguiente enunciado:

Mandóme (o por el afecto con que lo mira, o quizá porque estando enfermo divirtiese sus males con la noticia que yo le darías de los muchos míos) fuese a visitar a D. Carlos de Sigüenza y Góngora, cosmográfo y catedrático de matemáticas del Rey Nuestro Señor en la Academia Mexicana, y Capellán Mayor del Hospital Real del Amor de Dios de la ciudad de México (títulos son éstos que suenan mucho y valen muy poco, y a cuyo ejercicio le empeña más la reputación que la conveniencia). Compadecido de mis trabajos, no sólo formó esta relación en que se contienen, sino que me consiguió con la intercesión y súplicas que en mi presencia hizo al Excelentísimo Sr. Virrey, decreto para que D. Sebastián de Guzmán y Córdoba, factor, veedor y proveedor de las Cajas Reales me socorriese, como se hizo. (Siguenza y Góngora, 148-149)

Por extensión, el estatuto "literario" significa para Infortunios "su carácter eminentemente narrativo, el hecho de constituir una construcción literaria ficticia; no una novela contemporánea, pero sí ciertamente una novela [sic]" (Lagmanovich, 412). El artificio consiste en enunciar y dar forma a la síntesis de lo factual y lo ficcional en la narrativa, que no solo dará cuenta de hechos, implicando la ficción polifónica como instrumento que dará forma a hechos múltiples. En consecuencia, la Relación narrativa factual-ficcional, supera la oposición, que afectó los estudios de los textos del periodo colonial y parte del siglo XIX. Efectivamente, en algunas narrativas coloniales cambia la dinámica: a veces lo factual enmascara lo ficcional facilitando la reconstrucción del sentido del enunciado, en relación con el proceso de enunciación. De aquí, el papel que la isla de Puerto Rico (evidencia geográfica) cumple como espacio, en el mapa del imperio colonial e incorporado narrativamente en la peregrinación de Alonso Ramírez, desde su partida a los trece años. Igualmente significativas son las inferencias, respecto al origen marrano del padre y la estricta religiosidad católica de su madre. La relación entre el enunciado narrativo y las características del proceso de enunciación, permiten la interpretación en la cual, el Lector decide y elabora sentido, de acuerdo al diálogo con el contexto histórico cultural.

La consideración de Sigüenza y Góngora, Autor en Infortunios y de Alonso Ramírez, Narrador, en el contexto del siglo diecisiete (1690) ofrece un conjunto de problemas que implican los estudios literarios. El facsímil de los Infortunios de 
Alonso Ramírez de la edición original de 1690 Hispanic Society of America, muestra en portada el siguiente registro:

\section{INFORTUNIOS QUE}

ALONSO RAMIREZ

NATURAL DE LA CIUDAD DE S. JUAN

DE PUERTO RICO

padeció, allí en poder de Ingleses Piratas que lo apresaron

en las Islas Philipinas

como navegando por si solo, y fin derrota, hasta

varar en la Costa de Iucatan:

Consiguiendo por este medio dar vuelta al Mundo

\section{DESCRIVELOS}

D. Carlos de Siguenza y Gongora

Cosmografo, y Catedratico de Matematicas

Del Rey N. Señor en la Academia Mexicana

(Ilustración)

\section{CON LICENCIA EN MEXICO}

por los Herederos de la Viuda de Bernardo Calderon: en la calle de

S. Agustin, Año de 1690.

Carlos de Sigüenza y Góngora, enuncia la Autoría, como se lee en portada, dedicatoria y resumen que antecede cada capítulo, además organiza o edita la Peregrinación narrada en primera persona por Alonso Ramírez. La situación narrativa Autorial (SA) implica un YO editor que facilita la relación del narrador y del personaje: $\mathrm{A} \neq \mathrm{N}=\mathrm{P}$. El problema que introduce esta autoría, ha provocado a la vez, su negación:

Tan seguro estaba Menéndez y Pelayo que coloca su comentario sobre Infortunios en la sección de su Historia de la poesía hispanoamericana que corresponde a Puerto Rico (1; 329-33), y no en la de México.

Los notables eruditos puertorriqueños Cayetano Coll y Toste y Concha Meléndez concuerdan con el crítico español. (Irizarri, 12)

Igualmente se "ha preferido dejar sin resolver la cuestión de si existió o no Alonso Ramírez" (Irizarry, 12) (Claramente ya no se duda de su existencia) lo que nos dejaría sin autor y sin narrador, es decir puro registro. Sin embargo y en función del enunciado; las condiciones de la isla en el contexto del imperio español, constituyen evidencias junto con el itinerario desde San Juan de Puerto Rico a México y el registro del atestamiento marítimo de corsarios y piratas ingleses, holandeses, franceses que sirvieron a los imperios adversarios. También 
constituyen evidencias, las coordenadas náuticas y cartas geográficas de viajes a Filipinas, Manila, Oriente y África que implicó la peregrinación.

Hácese esta salida con la virazón por el oesnoroeste, o noroeste, que entonces entra allí como a las once del día; pero siendo más ordinaria por el sudoeste, y saliéndose al sur y sursudueste, es necesario para excusar bordos esperar a las tres dee la tarde, porque pasado el sol del meridiano alarga el viento para el oesnoroeste, y noroeste, y se consigue la salida sin barloventear. Navégase desde allí la vuelta del sur con las virazones de arriba ( $\sin$ reparar mucho en que se varíen las cuartas, o se aparten algo del meridiano) hasta ponerse en 12 gr. O en algo menos. (Siguenza y Góngora, 101)

La experiencia náutica y marítima del autor y del narrador, relaciona el enunciado y la enunciación. Este conocimiento se inscribe al final del capítulo uno y principios del capítulo dos. La incorporación al enunciado del geógrafo y matemático Sigüenza y Góngora, convocado por Alonso Ramírez en su relato, complejizan positivamente la síntesis factual con la ficcional. Luego el relato de la salida del Galeón Santa Rosa del puerto de Acapulco, final del capítulo uno y principios del dos, logra una narración (técnica) de las condiciones de navegación en grados y millas exactas, fusionando el conocimiento marítimo y náutico del narrador con el conocimiento cosmográfico de Sigüenza como autor. La ajustada trama de Infortunios calza perfectamente en la narrativa, constituyéndose como un relato muy sofisticado que no desmerece, frente al escrutinio literario ni tampoco histórico. Por otro lado, satisface no solo la demanda picaresca, sino también la hagiográfica: la peregrinatio como ejemplo de virtud a pesar de las vicisitudes y peripecias del viajero. El triunfo cristiano ante la acechanza protestante. Este nivel formal, efectivamente articulado en una narración integral, contradice el ceñidor de novela conceptualizada como "narraciones imaginarias que presentan un narrador ficticio, integran un lector ficticio y se refieren a un mundo; narraciones que adquieren una forma cerrada cuando acontecimiento, personaje y espacio se constituyen en el plano configurante" (Goic, 370), según paráfrasis de Wolfang Kayser y Martínez Bonati.

La narración incorporada por Infortunios de Alonso Ramírez a finales del siglo XVII, introduce refinados modos de tramar: Sigüenza y Góngora, incorporado a la narración, mediante aparatos nuncupatorios, marco capitular y enunciados específicos de Alonso Ramírez; narrador y personaje del peregrinaje, en un relato que no elude el humor y la aventura, también incorpora al lector con una agilidad desconocida en otros textos. La síntesis produce tensión entre poéticas, discursos, géneros, involucrando al lector en estrategias de validación de lo literario e histórico. Para Covarrubias la fábula "narración artificiosa, inventada" cumple con los requisitos de "un cuento bien compuesto o patraña para entretener los oyentes" (872). Alonso Ramírez relata: 
No puedo proseguir sin referir un donosísimo cuento que aquí pasó. Sabiéndose, porque yo se lo había dicho a quien lo preguntaba, ser esclavo mío el negrillo Pedro, esperando uno de los que me habían examinado a que estuviese solo, llegándose a mí y echándome los brazos al cuello, me dijo así: — ¿Es posible, amigo y querido paisano mío, que os ven mis ojos? Oh, cuántas veces se me han anegado en lágrimas al acordarme de vos: Quién me dijera que os había de ver en tanta miseria. Abrazadme recio, mitad de mi alma, y dadle gracias a Dios de que esté yo aquí. Preguntéle quién era y cómo se llamaba, porque de ninguna manera lo conocía.

- ¿Cómo es eso?, me replicó, cuando no tuvisteis en vuestros primeros años mayor amigo, y para que conozcáis el que todavía soy el que entonces era, sabed que corren voces que sois espía de algún corsario, y noticiado de ello el gobernador de esta provincia os hará prender, y sin duda alguna os atormentará. Yo por ciertos negocios en que intervengo tengo con su señoría relación estrecha y lo mismo es proponerle yo una cosa que ejecutarla. Bueno será granjearle la voluntad presentándole ese negro, y para ello no será malo el que me hagáis donación de él. (Siguenza y Góngora, 144-145)

Esta versión del cuento (del tío) en pleno siglo XVII, es una visión de la situación social, en esa "parte de la América" (129) como dice Alonso, que le reprocha sus embustes al mismo estafador, junto con proveer criterios acerca de lo que se considera cuento en el contexto de época.

En Infortunios la poética de la narración, involucra una estructura que fusiona perfectamente narrativas, evidencias y composición. La historia del narrador Alonso Ramírez se ajusta al marco autorial. David Boost dice que "Infortunios es uno de los últimos ejemplos del siglo XVII -tal vez el mejor- de la adaptación literaria de un hecho histórico" (González Echeverría, Pupo-Walker, 202).

Además, como ha observado Aníbal González, comprender Infortunios sólo como una ficción o sólo como una historia sería equivalente a no comprender la semejanza retórica entre lenguaje de ficción y el histórico que se daba en esa época [...]. A pesar de que las categorías de «historia» y «ficción» podrían haber producido formas diferentes de recepción literaria, las modalidades expresivas del discurso histórico y del de ficción eran extraordinariamente similares. (González Echeverría, Pupo-Walker, 209)

\section{Conclusiones}

Este trabajo sobre Naufragios [1542] de Alvar Núñez Cabeza de Vaca e Infortunios de Alonso Ramírez [1690] de Carlos de Sigüenza y Góngora y que 
propone la narrativa colonial hispanoamericana como síntesis de lo factualficcional, no pretende ser original ni busca afanes polémicos ${ }^{14}$. Desde 1492 el contexto de Indias, constituyó al mismo tiempo una realidad narrativa, registrada en obras y además la historización del proceso de construcción colonial. Sin embargo, de acuerdo a lo planteado, en el flujo enunciativo, no corresponde diferenciar referentes imaginados de referentes reales ${ }^{15}$. Es decir, la síntesis factualficcional en una sola narrativa, permitirá entender un conjunto de obras del periodo colonial, marginadas de los estudios, pues no satisfacían las demandas literarias ni historiográficas. La incorporación de estos textos, a un corpus para la educación e investigación literaria, constituyen una perspectiva de reformulación del canon. Reiteramos que en estudios precedentes, alguna de estas obras se siguen manteniendo ajenas a la reflexión: La peregrinación de Bartolomé Lorenzo [1586], La Araucana [1574-1589], Comentarios reales de los Incas (1609), Nueva Corónica y buen gobierno [1615], Historia de la monja alférez, Catalina de Erauso, escrita por ella misma [1653], Cautiverio feliz [1673], Los infortunios de Alonso Ramírez [1690], El lazarillo de ciegos caminantes [1776] por nombrar otras narrativas complejas, sumadas a las ya estudiadas. Según lo expuesto, el concepto de ficción no se debe limitar solo a fantasía (como facultad lesiva), sino que la ficción es forma de composición, cuyas evidencias históricas, geográficas, políticas, biográficas, culturales encajan sin violencia, con modos de tramar y componer textos, habituales en la experiencia de contar.

Por otro lado, el Autor como principio de clasificación textual, se ve enriquecido por el estudio de la situación Autorial, revelando las condiciones y contextos en que se produce la obra, dando sentido al enunciado y vinculando el Autor, en su diferencia o igualdad con el narrador y con el personaje. Esta perspectiva define mejor las Poéticas que determinan la estructura, modos de representación y lenguaje, tanto en Naufragios como en Infortunios. Igualmente, las evidencias no obstaculizan el placer de la lectura, pues el Lector, incorporado al ejercicio interpretativo, es vital para la recepción de lo narrado, incluso diríamos que, podríamos obviar información documental y desentendernos de nociones como Ficción vs realidad/Literatura vs historia/ Verdad vs verosimilitud, y otras.

Finalmente, no aspiramos a dar satisfacción a todas las preguntas vinculadas a las obras estudiadas, pero los objetivos y los problemas que se consideraron fueron abordados con el deseo de entender los problemas planteados.

${ }^{14}$ La primera versión de este trabajo fue presentada el 27 de enero 2017 en Center for Latin American Studies, CLAS University of Pittsburg con académicos y alumnos del Programa de Doctorado en Literatura e igualmente expusimos el trabajo con mínimos agregados el 2 de abril del mismo año en la Asociación alemana de Hispanistas en el XXI Congreso en Ludwig Maximilians Universitat en Munich. A partir de la discusión y de lo0s aportes recogidos en las dos instancias, tenemos la impresión que los problemas que incluyó nuestra investigación, no habían sido esclarecidos a pesar de la investigación previa.

15 "La verdad en la vida y la verdad en la (...) [narrativa] no son idénticas” Edward Morgan Foster en "Aspectos de la novela". Luciano Lamberti (2016): Cómo escribir. Buenos Aires: China editora. 121-165. 
CATEDRAL TOMADA: Revista de crítica literaria latinoamericana / Journal of Latin American Literary Criticism El discurso factual y ficcional en la narrativa colonial hispanoamericana: Naufragios [1542] de Alvar Núñez Cabeza de Vaca e Infortunios de Alonso Ramírez [1690] de Carlos de Sigüenza y Góngora.

\section{Bibliografía}

Abbagnano, Nicola (2010). Diccionario de Filosofía. México. FCE.

Adorno, Rolena (1988). "Nuevas perspectivas en los estudios coloniales latinoamericanos". Revista de Crítica Literaria Latinoamericana. Lima, 11-28.

Anadón, José 2015). Historiografía literaria latinoamericana colonialcontemporánea. Seminario de Cultura Mexicana. México D. F.

Covarrubias Horozco, Sebastián de (2006). Tesoro de la lengua castellana o española. Madrid: Iberoamericana.

Davis, Natalie Zemon (1987). Ficcion in the Archives. Stanford CA: Stanford University Press.

Doležel, Lubomír (1997). Historia breve de la poética. Madrid: Síntesis.

Genette, Gérard (1993). Ficción y dicción. Barcelona: Lumen.

Goic, Cedomil (1982): "La novela hispanoamericana colonial”. Luis Iñigo Madrigal. Historia de la Literatura Hispanoamericana. (Tomo I. Época Colonial). Madrid: Cátedra. 369-406.

Hachim, Luis (2010). "Esbozo de una narrativa del pensamiento crítico y literario en el periodo colonial". Discursos/prácticas Revista de Literaturas latinoamericanas, 3. Valparaíso. 11-23.

Invernizzi Santa Cruz, Lucía (1987): "Naufragios e Infortunios: Discurso que transforma fracasos en triunfos". Revista Chilena de Literatura (Universidad de Chile), $\mathrm{N}^{\circ} 29.7-22$.

Lagmanovich, David (1988): "Para una caracterización de Infortunios de Alonso Ramírez". Cedomil Goic. Historia y crítica de la Literatura hispanoamericana. Barcelona: Crítica. 411-416.

Lamberti, Luciano (2016): Cómo escribir. Buenos Aires: China editora.

Lejeune, Philippe (1994): El pacto autobiográfico. Madrid: MEGAZULENDYMION.

Merrim, Stephanie (2006): "Los primeros cincuenta años de historiografía hispana sobre el Nuevo Mundo: el Caribe, México y América Central”. González Echeverría, Roberto y Pupo-Walker, Enrique [Eds]. Historia de la Literatura Hispanoamericana I: Del Descubrimiento al Modernismo. Madrid, Gredos.

Núñez Cabeza de Vaca, Álvar (2015). Naufragios. Madrid: Alianza.

Ormeño, Claudia (2008). Narrativa del Barroco de Indias: Tres obras ocultas bajo la máscara realista. Tesis pregrado. Universidad de Santiago de Chile.

Pastor, Beatriz (1983). Discurso narrativo de la Conquista de América. La Habana: Casa de las Américas.

Quesada, Vicente (1917). La vida intelectual en la América española. Buenos Aires: La cultura argentina.

Quijano, Aníbal (2000): “Colonialidad del poder, eurocentrismo y América Latina". Edgardo Lander (Compilador) et Al. La colonialidad del saber: 
eurocentrismo y ciencias sociales. Perspectivas latinoamericanas.Buenos Aires: CLACSO. 201-246.

Recopilación de leyes de los Reynos de las Indias. Mandadas imprimir y publicar por la Magestad Católica del Rey Don Carlos II Nuestro Señor. Tomo primero. Madrid: por Iulian de Paredes 1681.

Reis, Carlos (2002): "Narratividad". Carlos Reis, Ana Lopes. Diccionario de Narratología. Salamanca: Almar. 166-175.

Ruiz Barrionuevo, Carmen (2008). “Introducción”. José Joaquín Fernández de Lizardi. El Periquillo Sarniento. Madrid: Cátedra.

Saer, Juan José (2015). Ensayos. Buenos Aires: Seix Barral.

Sigüenza y Góngora, Carlos de (1990). Infortunios de Alonso Ramírez. Estelle Irizarry (Edición) San Juan: Comisión puertorriqueña para la Celebración del Quinto Centenario del Descubrimiento de América y Puerto Rico.

Stanzel, F. K, (1984). A theory of narrative. Wiltshire: Cambridge University Press. 